(C) Baindurashvili A.G., Vissarionov S.V., Belianchikov S.M., Kartavenko K.A., Solokhina I.Iu., Kozyrev A.S., Pukhov A.M., Moshonkina T.R., Gerasimenko Iu.P., 2020

DOI 10.18019/1028-4427-2020-26-1-79-88

\title{
Comprehensive treatment of a patient with complicated thoracic spine injury using percutaneous electrical spinal cord stimulation (case report)
}

\author{
A.G. Baindurashvili ${ }^{1}$, S.V. Vissarionov ${ }^{1}$, S.M. Belianchikov ${ }^{1}$, K.A. Kartavenko ${ }^{1}$, I.Iu. Solokhina ${ }^{1}$, \\ A.S. Kozyrev' ${ }^{1}$ A.M. Pukhov ${ }^{2}$, T.R. Moshonkina ${ }^{3}$, Iu.P. Gerasimenko ${ }^{3}$ \\ ${ }^{1}$ The Turner Scientific and Research Institute for Children's Orthopedics, Saint Petersburg, Russian Federation \\ ${ }^{2}$ The Velikiye Luki State Academy of Physical Culture and Sports, Velikiye Luki, Russian Federation \\ ${ }^{3}$ Pavlov First St. Petersburg State Medical University, Saint Petersburg, Russian Federation
}

\begin{abstract}
Objective Demonstrate an outcome of comprehensive treatment of an adolescent with fracture-dislocation of the thoracic spine accompanied by deep lower paraplegia and pelvic floor dysfunction using noninvasive percutaneous spinal cord stimulation and mechanical stimulation of the foot bearing surface. Case study Comprehensive treatment was performed for a 17-year-old patient who sustained a combined injury during roller ski training. The patient presented with back pain, breathing difficulty, being unable to perform active movements of lower extremities. He reported loss of sensitivity in the lower part of the body, perineum and lower limbs. The injury was classified as ASIA grade B with motor impairment scored 50 and overall sensory score of 88 . Surgical intervention was produced within the first hours after injury and was followed by rehabilitation program including stimulation of the foot bearing surface with Korvit plantar support load simulator and noninvasive percutaneous spinal cord stimulation. Neurologic status of the patients was graded as ASIA level D at one-year follow-up with motor score of 85 and sensory level improved to 175 . Conclusion Surgical treatment produced for the patient with spinal cord injury within the first hours after trauma using noninvasive percutaneous spinal cord stimulation and mechanical stimulation of the foot bearing surface provided regress of neurological disorders facilitating more intense lower-limb motor recovery and other important gait characteristics. The patient could regain voluntary control of muscle activity, stand unassisted and walk with a cane at one year post-injury.
\end{abstract}

Keywords: spinal cord injury, spinal stenosis, noninvasive percutaneous spinal cord stimulation

\section{INTRODUCTION}

The occurrence of traumatic spinal cord injuries (TSCI) is on the rise among pediatric population. Unstable and complicated TSCI represent $<2 \%$ of the overall incidence of pediatric SCI with the severity increasing over the last few years. In 2010, pediatric unstable spine injuries accounted for 85.7 $\%$ and $14.3 \%$ fell on complicated spine trauma according to statistical report of pediatric SCI in St.Petersburg and Leningradskaya Oblast. In 2017, pediatric unstable fractures represented $67.7 \%$ with SCI accounting for $32.4 \%$. Pediatric SCI is associated with a risk of developing secondary conditions, devastating complications and significant physiological consequences. Survival rate for individuals younger than 29 years who sustained SCIs at the thoracic, thoracolumbar or lumbar levels is rather high and constitutes $86 \%$ of the injured in this age group. There are a lot of studies in the literature recently that are looking into the most commonly available surgical options for individual types and severity of SCI. Evidence suggests early surgical intervention is safe and effective for injuries with vertebral dislocation, spinal stenosis and neurologic deficits. A combination of the initial extent of the injury, particular injury pattern, the level of injury, severity of neurologic deficit, timing of surgery, physical therapy and rehabilitation are thought to have a significant impact on overall recovery of sensorimotor function and walking ability in patients with SCI. The goals of surgical management for SCI are to correct posttraumatic deformity in all planes, eliminate spinal stenosis, decompress the neural

[Daindurashvili A.G., Vissarionov S.V., Belianchikov S.M., Kartavenko K.A., Solokhina I.Iu., Kozyrev A.S., Pukhov A.M., Moshonkina T.R., Gerasimenko Iu.P. Comprehensive treatment of a patient with complicated thoracic spine injury using percutaneous electrical spinal cord stimulation (case report). Genij Ortopedii, 2020, vol. 26, no 1, pp. 79-88. DOI 10.18019/1028-4427-2020-261-79-88. (In Russian) 
elements, stabilize the injured spinal motion segment with metal construct, promote potential for early ambulation, induce recovery from neurologic deficits at segmental levels. There is limited information in the literature about motor and sensory recovery in pediatric patients with SCI. Although the commonly used criteria, guidelines and approaches for operative management of complicated SCIs including guideline recommendations supporting the safety of early surgery are consistently followed neurological improvement is rarely seen in ASIA A\&B patients.

Objective: To demonstrate an outcome of comprehensive treatment of an adolescent with fracture-dislocation of the thoracic spine accompanied by deep lower paraplegia and pelvic floor dysfunction using noninvasive percutaneous spinal cord stimulation and mechanical stimulation of the foot bearing surface during rehabilitation.

\section{CASE REPORT}

A 17-year-old sustained a combined injury while roller ski training. He fell down and experienced a short period of unconsciousness, involuntary urination and defecation. Immediately after trauma, having regained consciousness he experienced intense back pain, difficult breathing and was unable to move the lower limbs. He reported loss of sensation in the lower part of the body, perineum and legs. He was transported to a regional hopsital of the Leningradskaya Oblast by emergency medical services and the care was provided for his vital organs over 3 hours. The right-side pleural space was evacuated with Redon drain. He received the anti-oedema therapy, support for cerebral protection (cytoflavin ceraxone), hemostatic (dicynone, vicasolum, gordoxum), antimicrobial (ceftriaxone $2.0 \mathrm{~g} \times 2$ twice/ day, metrogyl mg $\times$ twice/day), infusion, hormone therapy and NSAIDs, promedolum for pain relief. $\mathrm{He}$ was transferred to the Turner Scientific and Research Institute for Children's Orthopedics Minzdrava Rossii after 3 hours of injury with a severe spinal trauma and neurological deficits identified. The patient was admitted to the hospital with functioning pleural drainage placed through the second intercostal space in the right midsubaxillary line at the the sixth intercostal space, with the access to the central venous circulation via the right subclavian vein catheterization. He presented with multiple abrasions and hematomas over the body and across the upper and lower limbs, symmetrical rhythmical pulse 96 beats per minute, satisfactory cardiac pump, blood pressure 110/70 $\mathrm{mmHg}$, concise and clear cardiac sounds, asymmetrical chest excursion (Sin > Dex) with decreased amplitude. Auscultation of the lungs revealed vesicular breath sounds heard through the chest wall on the right with no rattling. The abdomen was slightly swollen, symmetrical, participating in breathing, soft, pain free, being accessible to deep palpation everywhere; weak peristalsis, urine drained via urinary catheter being light yellow and clear without pathological admixtures. Neurological findings included normal state of consciousness, adequate orientation in space and time; the palpebral apertures $\mathrm{D}=\mathrm{S}$, pupils $\mathrm{OD}=\mathrm{OS}=2.0 \mathrm{~mm}$ being equal, round and reactive to light and accommodation, fine horizontal nystagmus in extreme positions of gaze, symmetry observed in the face, the tongue remaining on the midline when protruded; swallowing and voice quality being intact; full active motion in the upper limbs with sufficient muscle strength, similar vital tendon reflexes; no voluntary motion seen in the lower limbs and tendon reflexes evoked; muscle tone being satisfactory in the upper limbs and reduced to anotia in the lower limbs, impaired deep and superficial sensation from Th4-5 level; no abdominal reflexes evoked; perianal reflexes persisted, Sph. ani being not dehisced; no meningeal signs observed; pelvic floor dysfunction diagnosed. The injury was classified as ASIA grade B with motor impairment scored 50 and overall sensory score of 88 (Fig. 1).

Laboratory tests indicated to compensated condition. No cardiac pathology was detected with ECG. US of the abdomen and kidneys showed nonreflex bladder.

Radiographic examination and MSCT performed on 21.07.2017 showed fracture-dislocation of the thoracic spine at the Th5-6 level (AO type C), spinal stenosis, pulmonary contusion with signs of rupture affecting the right lower lobe, bilateral small hemothorax, fractures of the clavicle and scapula on the right, broken transverse processes of Th3-Th8 vertebrae on the left (Fig. 2).

MRI examination of the brain, cervical, thoracic and lumbosacral spine and the spinal cord showed no signs of cerebral contusion and swelling. 


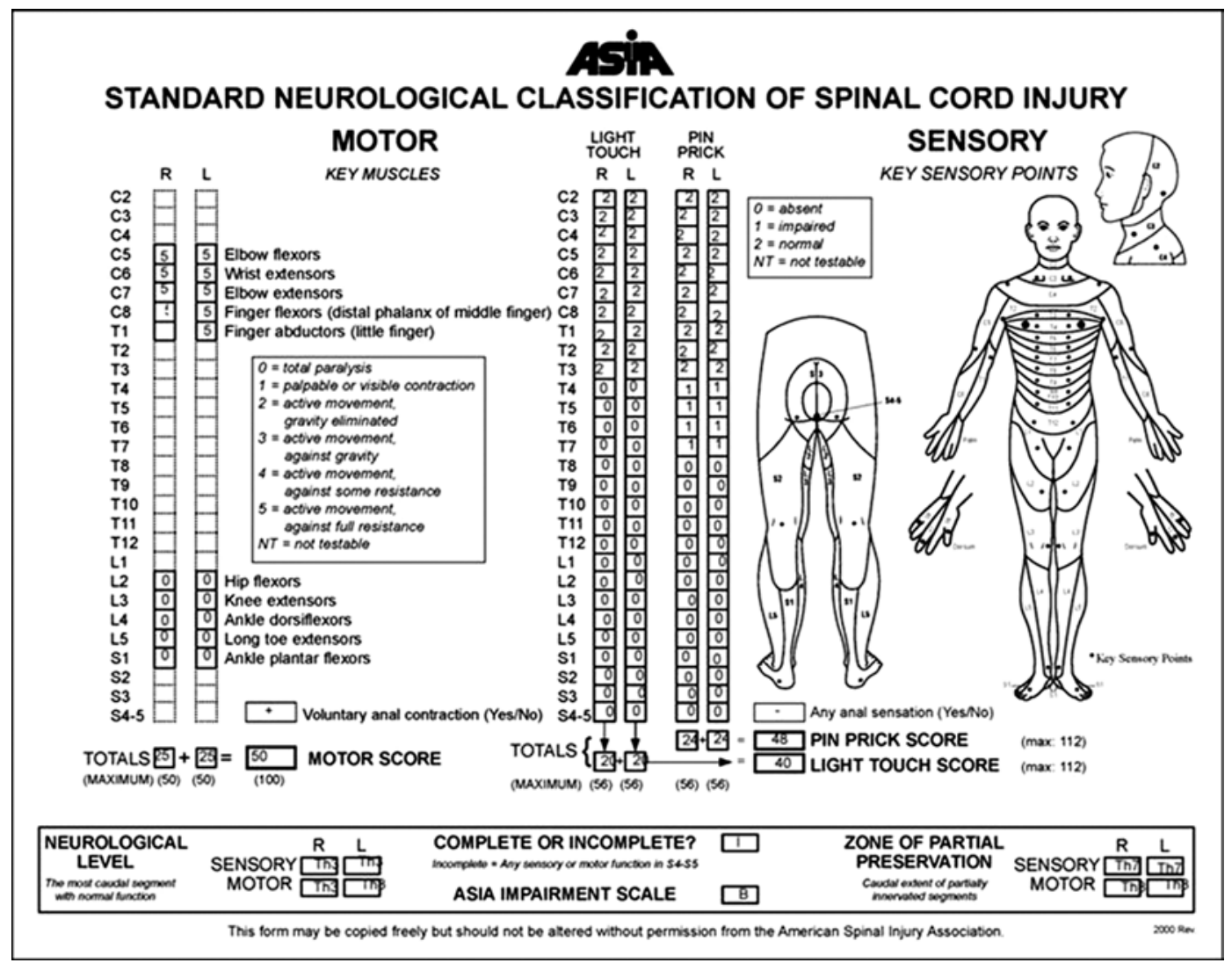

Fig. 1 Neurological impairment in a 17-year-old patient evaluated with ASIA scoring sheet
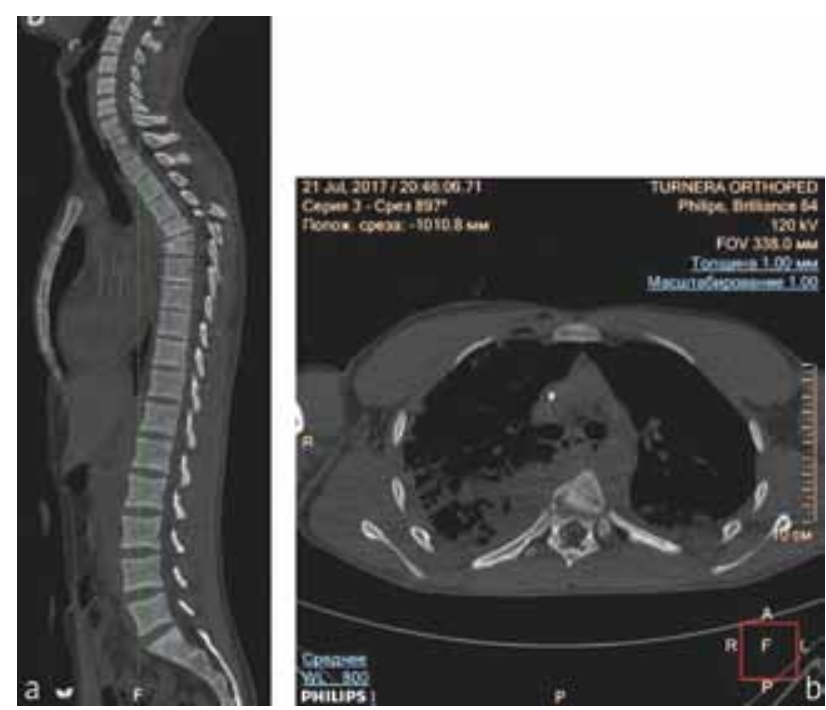

Fig. 2 CT scans of the spinal column showing fracturedislocation of the Th5-Th6 vertebrae in (a) sagittal and (b) axial planes

Physical, neurological assessment, laboratory testing, functional and imaging studies performed for the patient revealed severe combined spinal cord injury, closed traumatic brain injury, cerebral concussion, closed fracture-dislocation of the Th56 vertebrae (AO type $\mathrm{C}$ ), fracture of the transverse processes of Th3-Th8 vertebrae on the left, spinal stenosis at the Th5-6 level, cerebral contusion,

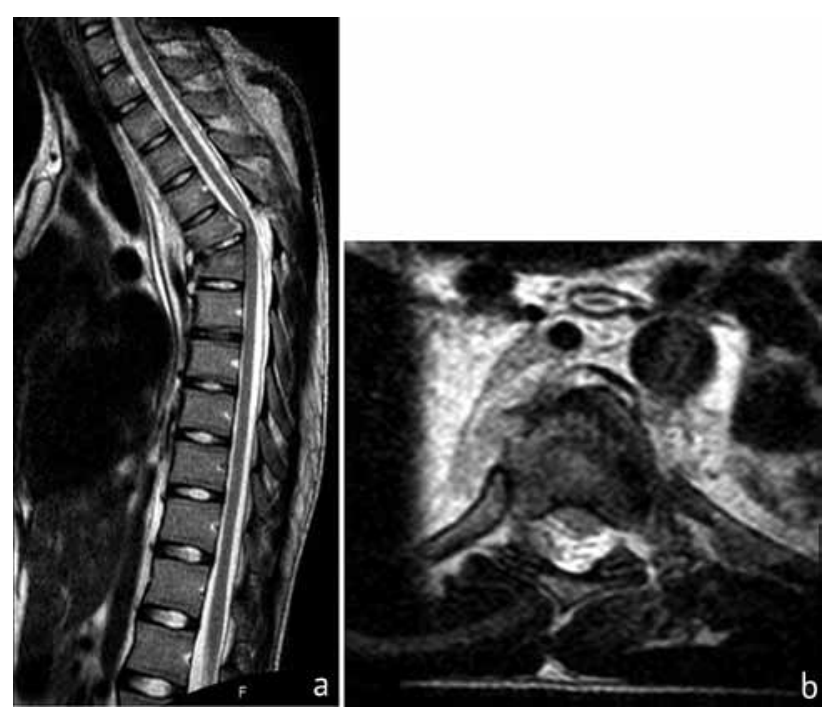

Fig. 3 MRI scans of the spinal column showing fracturedislocation of the Th5-Th6 vertebrae and contusion of the spinal cord in (a) sagittal and $(\boldsymbol{b})$ axial planes

lower paraplegia and pelvic floor dysfunction, non-reflex bladder, right-side hemopneumothorax following drainage, right-sided pulmonary contusion, straightforward closed fracture of the right clavicle.

An emergency surgical procedure performed on 21-22.07.2017 included circular decompression of the spinal cord at the Th5-Th6 level to address spinal stenosis, realignment and stabilization of the spine 
with multisupport transpedicular metal construct, posterior fusion using autologous graft, corporodesis, primary surgical treatment of bruises on the body and the upper and lower limbs. Skin incision was produced from Th2 to Th10 along the spinous process line and subgaleal haemorrhage identified at the thorcacic throughout the surgical approach. Dorsal Th5-Th6 bone structures appeared to be impaired and Th5 vertebral arch intruded into the spinal canal compromising the lumen of the spinal canal. Dural sac compression by the Th5 arch was such that the pulse could not be detected. Fractures of the transverse processes of Th2-Th8 vertebrae and the costovertebral joint of Th6 were identified on the left. Reconstruction of the spinal canal and circular decompression of the spinal cord were produced at the Th5-Th6 level with injured disc removed and vertebral bodies partially resected to address stenosis and dural sac compression at the level. Durac sac physiological position was regained with no injury found and pulse resumed. Transpedicular screws were bilaterally placed in the Th3, Th4, Th7, Th8, Th9 vertebral bodies and in the Th6 on the right. Posttraumatic vertebral deformity and all types of vertebral dislocations were eliminated with segmental correction followed by corporodesis of the postresection Th5-Th6 bone. Local posterior fusion was produced (Fig.4) and the Uno-Vac wound drainage system placed. The deso bandage was used to immobilize the clavicle and the right shoulder.
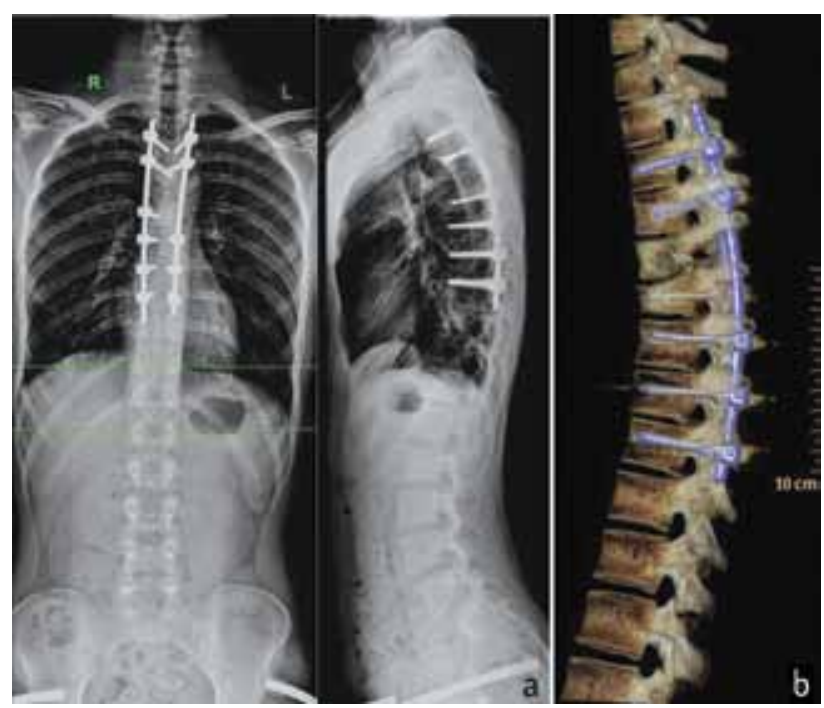

Fig. 4 AP and lateral spondylograms (a) and 3D reconstruction $(\boldsymbol{b})$ of CT image of the patient's spinal column postsurgery
Postoperative neurological deficit was evaluated as ASIA type B. Mechanical ventilation was provided postoperatively within 12 hours. Colloid and crystalloid solutions, albumin, plasma blood administered via an intravenous infusion were used for fluid replacement according to NASCIS-3 protocol, maintenance of spinal cord perfusion pressure performed with dopamine (5 $\mathrm{mkg} / \mathrm{kg}$ per minute for 3 days), prophylaxis of venous thromboembolism provided. Methylprednisolone was given in a dose of $5 \mathrm{mg} / \mathrm{kg}$ for 3 days. Stimulation of the foot bearing surface with Korvit plantar support load simulator was initiated on the second day postsurgery with 10 procedures performed in acute postoperative period. Starting on the 4 th day postsurgery active motor rehabilitation with regained spinal supportability included respiratory exercises (up to eight sessions/day), massage of the collarbone area, upper and lower limbs, gluteal area, exercise therapy to adapt to vertical loads on inclined planes, excercises for lower limbs using different objects and Ekzart therapy (Fig. 5).

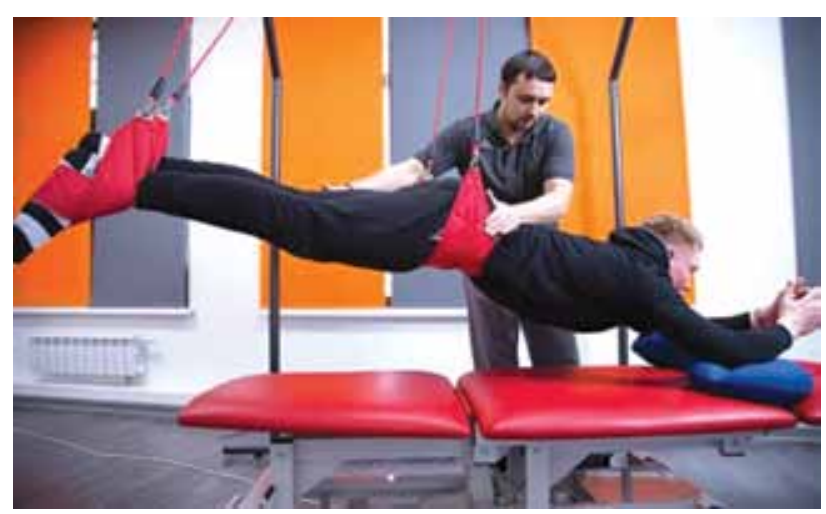

Fig. 5 Ekzart kinesiological unit

Noninvasive percutaneous spinal cord stimulation was initiated after eight postoperative days. Two stimulating BF-4 self adhesive round electrodes (LEAD-LOC Inc., USA) with diameter of $3 \mathrm{~mm}$ (cathodes) were placed between spinous processes of Th11-Th12 and L1-L2 vertebrae. Indifferent self adhesive oval electrodes (anodes) $10 \mathrm{~cm}$ long were located symmetrically over iliac crests. The stimulation frequency ranged from 5 to $30 \mathrm{~Hz}$ with the stimulation current intensity determined for each session individually depending on patient's sensations or appearance of motion in the lower limbs. The current intensity ranged between 20 and $90 \mathrm{~mA}$ with 
the strength increasing with each procedure that lasted for 30 minutes performed once a day during 10 days. Positive neurological dynamics was observed after 14 days of comprehensive rehabilitation program with improved sensations from Th6-Th7 level and visible contractions of the femoral muscles. Sensation in the lower limbs (mosaic type with hyperesthesia areas) developed after 20 days. Superficial sensations (pain thermal tactile) were the first to recover followed by improved proprioception. Sensation continued to improve with each other day. Motion in the ankle, hip and ankle joints, in the distal segments of the foot (dorsiflexion, movements of toes) was observed after 21 postoperative days with the course of comprehensive rehabilitation. The patient could consider flexion and extension in the knee joints, shortly holding the lower limbs with the knee and hip joints flexed. Neurologic status of the patient was graded as ASIA type $\mathrm{C}$ at a 30-day follow-up with motor score of 70 and sensory level improved to 130 . By the time, he improved his muscle strength in the proximal parts of the lower limbs to 2 points and could feel pressure on the bladder developing partial control of urination and defecation. During the next 4 months, the patient had individualized exercise program performing on a regular basis for 1.5-2 hours/day on his own and could adapt himself to sitting increasing the time for position by $5-10$ minutes daily. He also received courses of massage to the spine and the limbs, training of upright position with use of bracing for the knees and hips. He was able to walk at a 6-month followup using walking aids. He was seen at the outpatient clinic once every three months. His neurologic status was graded as ASIA level D at one-year follow-up with motor score of 85 and sensory level improved to $175(91+84)$ (Fig. 6).

Figure 7 shows photographs demonstrating stages of motor recovery. At 30-day follow-up, the patient could produce voluntary movements in the knee and ankle joints lying on his back following 10 procedures of noninvasive percutaneous spinal cord stimulation and 14 procedures of stimulation to the foot bearing surface with plantar support load simulator $(\boldsymbol{a})$. Next stage of rehabilitation included keeping upright position and standing unassisted $(\boldsymbol{b})$. He was able to initiate short steps using supporting frame. He could alternate weight-bearing on the legs, stepping with another leg and resumed standing. Similar training was provided for another side (c). At 6-month followup, he could walk on a plain surface using a cane and the support from physiotherapist $(\boldsymbol{d})$. Finally, at a 12-month follow-up, he felt coordinated walking on a plain surface using a cane $(\boldsymbol{e})$.

Results of neurophysiological examination at the last stage of treatment showed that walking on the treadmill holding the bars was accompanied by well coordinated rhythmical EMG-activity on lower limb muscles. Noninvasive electrical stimulation with frequency of $30 \mathrm{~Hz}$ at Th11-Th12 level was shown to improve his gait (Fig. 8).

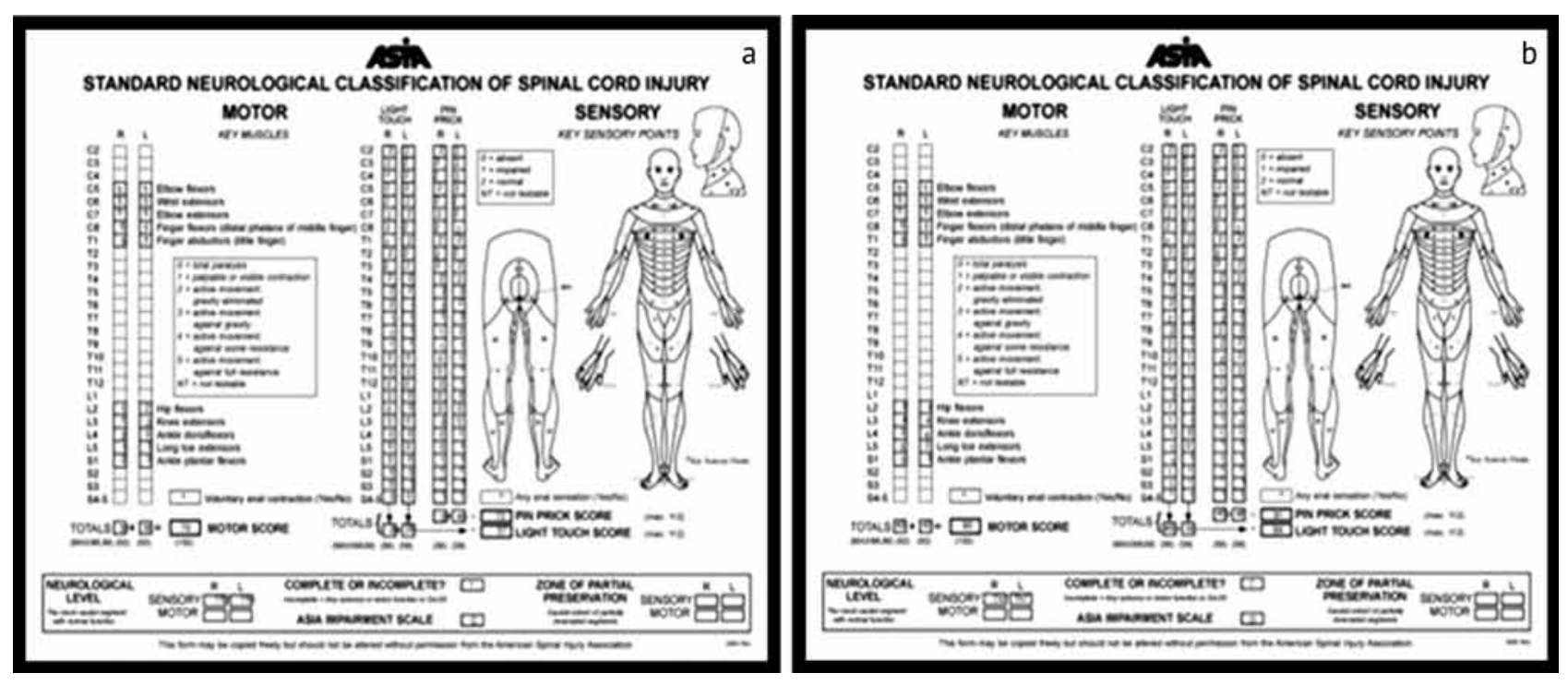

Fig. 6 ASIA dynamics in recovery of neurological status of the patient (a) at six months and $(\boldsymbol{b})$ at a 12-month follow-up 

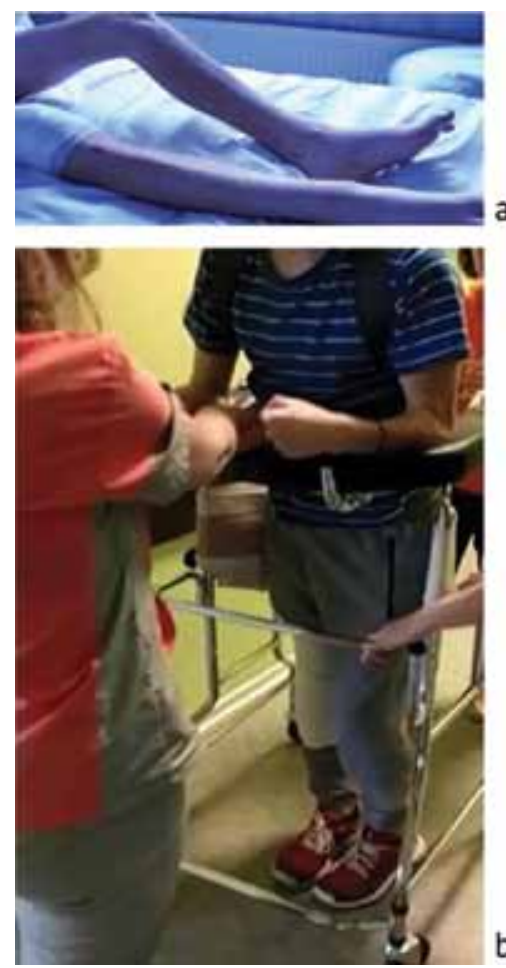
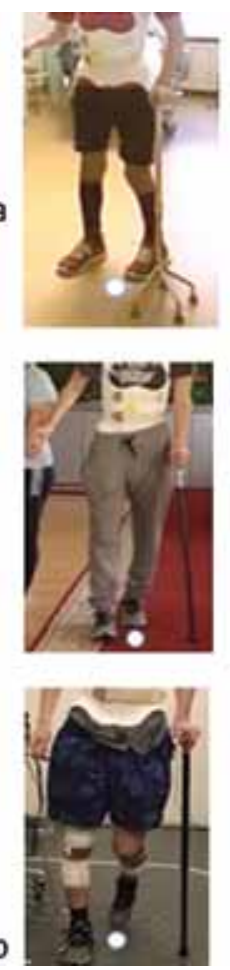
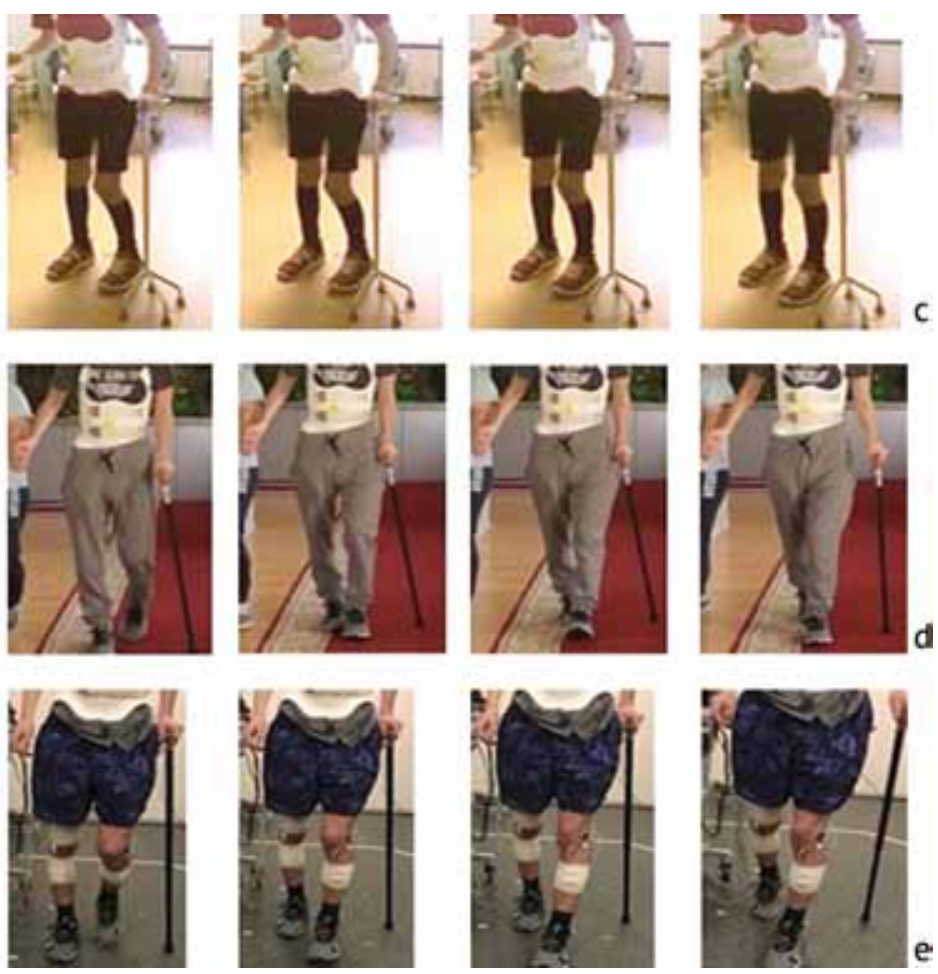

Fig. 7 Stages of motor recovery in the 17-year-old patient showing $(\boldsymbol{a})$ voluntary leg movements lying on his back, $(\boldsymbol{b})$ standing using support with the frame, $(\boldsymbol{c})$ initiation of the first steps, $(\boldsymbol{d})$ the gait with a cane and the support from physiotherapist, $(\boldsymbol{e})$ coordinated gait with a cane
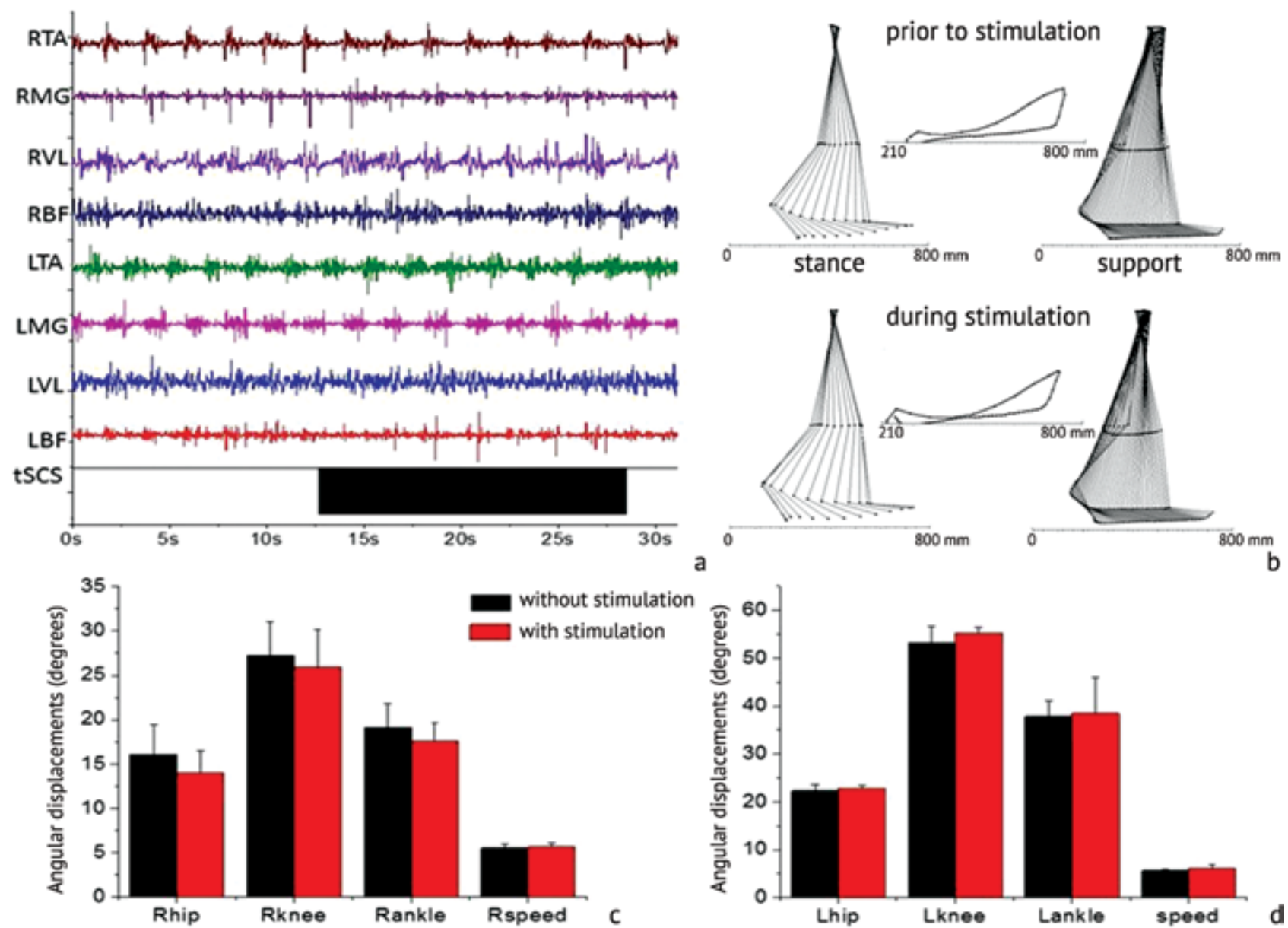

a
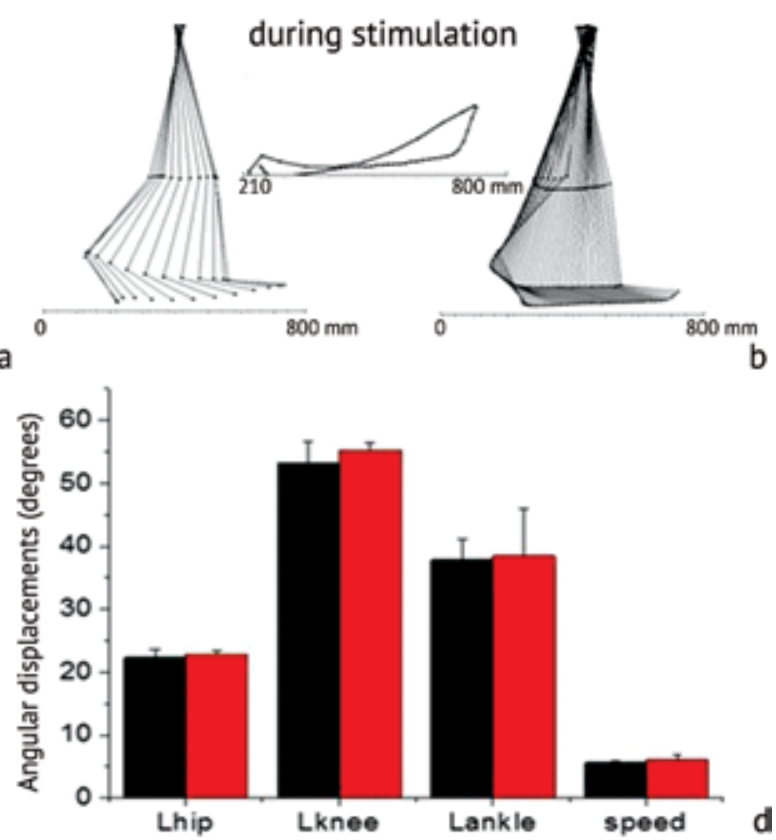

Fig. 8 Electromyographic and kinematic gait characteristics during treadmill walking with/without spinal cord stimulation: (A) EMG-activity of lower limb muscles: RTA, right tibialis anterior, RMG, right medial gastrocnemius, RVL, right vastus lateralis, RBF, right biceps femoris, LTA, left tibialis anterior, LMG, left medial gastrocnemius, LVL, left vastus lateralis, LBF, left biceps femoris, tSCS, spinal cord stimulation; (B) gait reconstruction prior to and during spinal cord stimulation; (C and D) histograms of angular displacements in the hip, knee and ankle joints at the gait. Speed, endpoint trajectory speed 
Endpoint trajectory in the left leg (marker moving with the toe) measured $0.98 \mathrm{~m}$ (amplitude $47 \mathrm{~mm}$ ) without stimulation while the measurements increased to $1.02 \mathrm{~mm}$ and $50 \mathrm{~mm}$, respectively, with spinal cord stimulation. Nonstimulation endpoint trajectory in the right leg measured $1.0 \mathrm{~m}$ (amplitude $60 \mathrm{~mm}$ ) and increased to 1.02 and $68 \mathrm{~mm}$, respectively, with spinal cord stimulation. Histograms presented in Figures $8 \boldsymbol{c}$ and $\boldsymbol{d}$ show angular displacement in the hip, knee and ankle joints of both sides at the gait. Spinal cord stimulation demonstrated increase in the range of motion (ROM) in the left knee and decrease in ROM in the right knee joint $(\boldsymbol{c}, \boldsymbol{d})$. Spinal cord stimulation effect was evident at the gait on a plain surface making stance shorter and step frequency longer (Fig. 9). Endpoint trajectory in the right leg measured $0.94 \mathrm{~m}$ without spinal cord stimulation and $0.79 \mathrm{~m}$ with stimulation. Endpoint trajectory in the left leg measured $0.87 \mathrm{~m}$ without spinal cord stimulation and $0.69 \mathrm{~m}$ with stimulation. Shorter stance with spinal cord stimulation could be associated with decreased ROM in the ankle joint taking into consideration measurements of angular displacement in several joints $(\boldsymbol{c}, \boldsymbol{d})$.
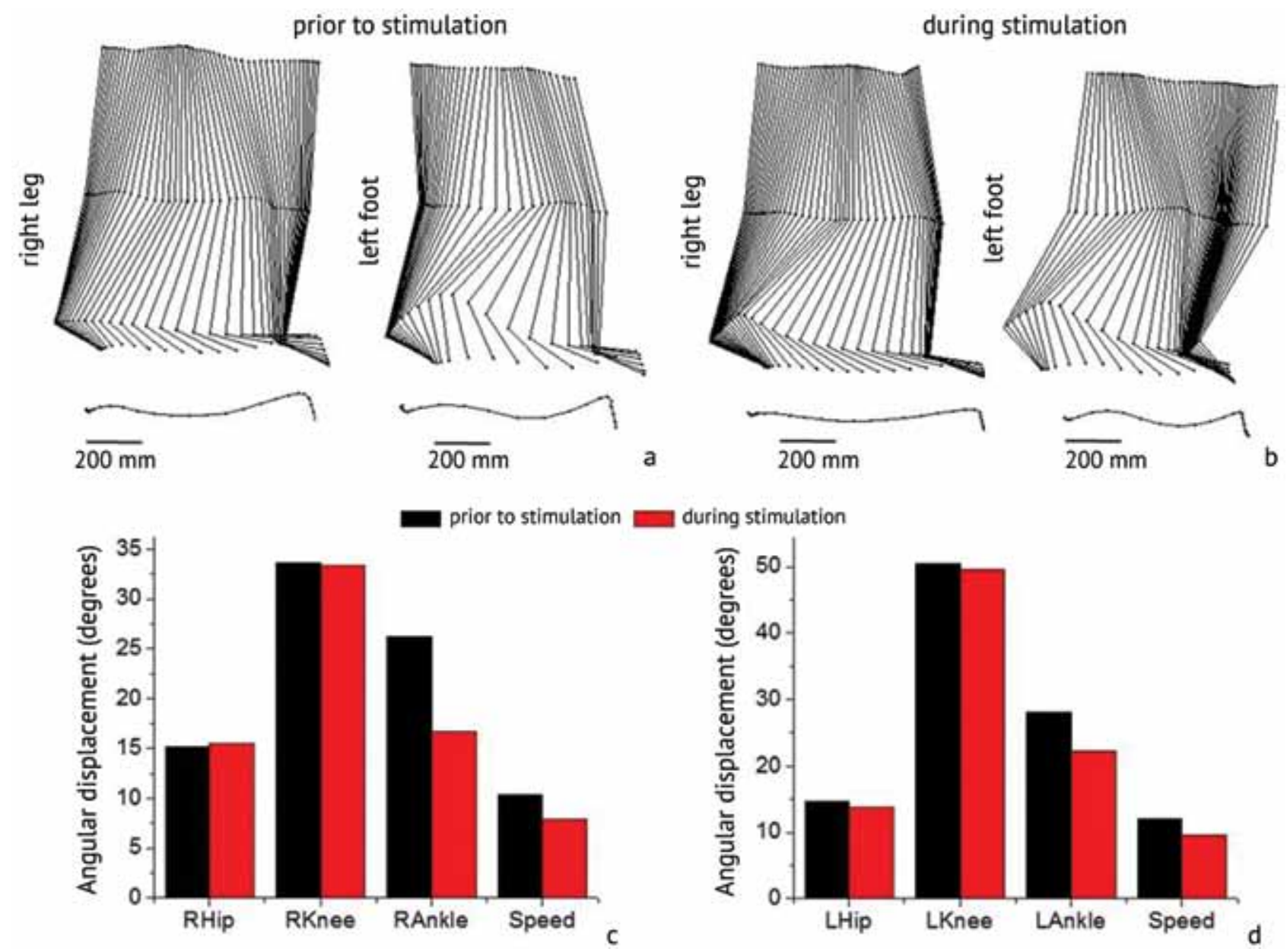

Fig. 9 Kinematic gait characteristics at walking on plain surface with spinal cord stimulation. Gait reconstruction of the left and right legs prior to $(A, B)$ and during $(C$ and $D)$ spinal cord stimulation.

\section{DISCUSSION}

There is limited information in the literature about motor and sensory recovery in pediatric patients with SCI. Most of the studies are looking into the most commonly available surgical options for individual types and severity of SCI and timing of surgery. Early surgical treatment, within the first hours of injury, should be strongly considered for patients suffering
SCI. However, a combination of the initial extent of the injury, particular injury pattern and the level of spinal cord injury have a significant impact on overall recovery of sensorimotor function in patients with SCI in addition to eliminated vertebro-medullary conflict. Rehabilitation of somatically stable patients commences straight after the surgery and is aimed 
at the therapy of the SCI severity by modulating physiological condition for the spine that rests on three major principles: 1) neuronal chains modulation to provide physiological position of the body and the limbs with supplementary passive rehabilitation of limb segments; 2) pharmacological modulation of neuronal chains; 3) modulation of physiological function of the spinal cord using electrical stimulation (functional, transcutaneous, epidural).

The role of noninvasive electrical stimulation of the spinal cord is scrutinized as a measure of providing sensorimotor function for SCI patients with restorative treatment at a long term. The series support positive electrical effect on the study parameters (transient and permanent improvements in sensorimotor function, muscle strength, etc.). We have not encountered series in the available literature reporting rehabilitation of SCI patients at early postoperative period with the assessment of dynamics in sensorimotor function in pediatric population. The surgical procedure performed for the reported SCI case within the first hours of injury was shown to contribute to the success of his rehabilitation period. Rehabilitation program with transcutaneous spinal cord stimulation and mechanical stimulation of the foot bearing surface ensured proper and more intense staged recovery of sensorimotor function. To our knowledge, most of pediatric patients with complicated spinal injury, thoracic spine, in particular, with clinical signs of neurological deficits (ASIA A and B) does not develop motor recovery after surgial treatment and rehabilitation. In a best-case scenario, this cohort of patients can demonstrate improved sensory function and bladder and bowel control that would require years of persistent efforts. Considerable positive dynamics in the reported pediatric case with thoracic SCI was achieved due to the timely surgical treatment and appropriate comprehensive therapy using noninvasive methods for the spinal cord recovery. The pediatric patient could get on his feet at a six-month follow-up and improve his neurological status from ASIA B to ASIA level D at a one-year follow-up.

\section{CONCLUSION}

Surgical treatment produced for the patient with SCI within the first hours after trauma using new method of noninvasive transcutaneous spinal cord stimulation and mechanical stimulation of the foot bearing surface provided regress of neurological disorders facilitating more intense lower-limb motor recovery and improvements in body weight support and gait in the early phase of rehabilitation. The patient could regain voluntary control of muscle activity, stand unassisted and walk with a cane at one year post-injury.

\section{REFERENCES}

1. Zaletina A.V., Vissarionov S.V., Baindurashvili A.G., Kokushin D.N., Soloveva K.S. Povrezhdeniia pozvonochnika i spinnogo mozga u detskogo naseleniia [Injuries of the spine and spinal cord among children]. Mezhdunarodnyi Zhurnal Prikladnykh $i$ Fundamentalnykh Issledovanii, 2017, no. 12-1, pp. 69-73. (in Russian)

2. DulaevA.K., Manukovskii V.A., Kutianov D.I., Bulakhtin Iu.Iu., Brizhan S.L., Zhelnov P.V. Sovershenstvovanieorganizatsii okazaniia neotlozhnoi spetsializirovannoi khirurgicheskoi pomoshchi patsientam $\mathrm{s}$ travmatich $\mathrm{s}$ travmaticheskimi i netravmaticheskimi porazheniiami pozvonochnika v usloviiakh megapolisa [Improving the organization of emergency specialized surgical care for patients with traumatic and non-traumatic injuries of the spine in the conditions of megalopolis]. Vestnik Khirurgii im. I.I. Grekova, 2017, vol. 176, no. 4, pp. 39-43. (in Russian)

3. Rajasekaran S., Vaccaro A.R., Kanna R.M., Schroeder G.D., Oner F.C., Vialle L., Chapman J., Dvorak M., Fehlings M., Shetty A.P., Schnake K., Maheshwaran A., Kandziora F. The value of CT and MRI in the classification and surgical decision-making among spine surgeons in thoracolumbar spinal injuries. Eur. Spine J., 2017, vol. 26, no. 5, pp. 1463-1469. DOI: 10.1007/s00586016-4623-0.

4. Daminov V.D., Kucherenko S.S., Sagildina Iu.Iu., Kuznetsov A.N. Robotizirovannye tekhnologii v reabilitatsii bolnykh posle khirurgicheskoi revaskuliarizatsii mozga [Robotic technologies in rehabilitation of patients after surgical brain revascularization]. Vestnik Vosstanovitelnoi Meditsiny, 2012, no. 2 (48), P. 29-31. (in Russian)

5. Alpantaki K., Bano A., Pasku D., Mavrogenis A.F., Papagelopoulos P.J., Sapkas G.S., Korres D.S., Katonis P. Thoracolumbar burst fractures: a systematic review of management. Orthopedics, 2010, vol. 33, no. 6, pp. 422-429. DOI: 10.3928/0147744720100429-24. 
6. Tang H.Z., Xu H., Yao X.D., Lin S.Q. Single-stage posterior vertebral column resection and internal fixation for old fracturedislocations of thoracolumbar spine: a case series and systematic review. Eur. Spine J., 2016, vol. 25, no. 8, pp. $2497-2513$. DOI: 10.1007/s00586-015-3955-5.

7. Baindurashvili A.G., Vissarionov S.V., Aleksandrovich Iu.S., Pshenisnov K.V. Pozvonochno-spinnomozgovaia travma u detei [Spinal and spinal-cord injury in children]. SPb., Onli-Press, 2016, 88 p. (in Russian)

8. Vissarionov S.V., Belianchikov S.M., Solokhina I.Iu., Ikoeva G.A., Kokushin D.N. Nevrologicheskie narusheniia u detei s oslozhnennymi povrezhdeniiami pozvonochnika $\mathrm{v}$ grudnom i poiasnichnom otdelakh do i posle khirurgicheskogo lecheniia [Neurological disorders in children with complicated injuries of the thoracic and lumbar spine before and after surgical treatment]. Khirurgiia Pozvonochnika, 2014, no. 3, pp. 8-21. (in Russian) DOI:10.14531/ss2014.3.8-21.

9. Baindurashvili A.G., Solokhina I.Iu., Kokushin D.N., Belianchikov S.M. Analiz vliianiia razlichnykh faktorov na dinamiku nevrologicheskikh narushenii u detei s pozvonochno-spinnomozgovoi travmoi [Analysis of the influence of various factors on the course of neurological disorders in children with spinal-and-spinal-cord injury]. Ortopediia, Travmatologiia i Vosstanovitelnaia Khirurgiia Detskogo Vozrasta, 2015, vol. 3, no. 4, pp. 12-21. (in Russian) DOI: 10.17816/PTORS3412-21.

10.Page B.J. Thoracic Spine Fractures and Dislocations. Poduval M., Chief Ed. Medscape. 2018. URL: https://emedicine.medscape. com/article/1267029-overview.

11.Smith W.D., Ghazarian N., Christian G. Acute and Hyper-acute Thoracolumbar Corpectomy for Traumatic Burst Fractures Using a Mini-open Lateral Approach. Spine, 2018, vol. 43, no. 2, pp. E118-E124. DOI: 10.1097/BRS.0000000000002244.

12.Bracken M.B., Shepard M.J., Holford T.R., Leo-Summers L., Aldrich E.F., Fazl M., Fehlings M., Herr D.L., Hitchon P.W., Marshall L.F., Nockels R.P., Pascale V., Perot P.L. Jr., Piepmeier J., Sonntag V.K., Wagner F., Wilberger J.E., Winn H.R., Young W. Administration of methylprednisolone for 24 or 48 hours or tirilazad mesylate for 48 hours in the treatment of acute spinal cord injury. Results of the Third National Acute Spinal Cord Injury Randomized Controlled Trial. National Acute Spinal Cord Injury Study. JAMA, 1997, vol. 277, no. 20, pp. 1597-1604. DOI: 10.1001/jama.277.20.1597.

13.Falavigna A., Righesso O., Guarise da Silva P., Sanchez Chavez F.A., Sfreddo E., Pelegrini de Almeida L., Valencia Carrasco M.J., Joaquim A.F. Epidemiology and Management of Spinal Trauma in Children and Adolescents < 18 Years Old. World Neurosurg., 2018, vol. 110, pp. e479-e483. DOI: 10.1016/j.wneu.2017.11.021.

14.Donenberg J.G., Fetters L., Johnson R. The effects of locomotor training in children with spinal cord injury: a systematic review. Dev. Neurorehabil., 2019, vol. 22, no. 4, pp. 272-287. DOI: 10.1080/17518423.2018.1487474.

15.Jazayeri S.B., Beygi S., Shokraneh F., Hagen E.M., Rahimi-Movaghar V. Incidence of traumatic spinal cord injury worldwide: a systematic review. Eur. Spine J., 2015, vol. 24, no. 5, pp. 905-918. DOI: 10.1007/s00586-014-3424-6.

16.Lee D.Y., Park Y.J., Song S.Y., Hwang S.C., Kim K.T., Kim D.H. The Importance of Early Surgical Decompression for Acute Traumatic Spinal Cord Injury. Clin. Orthop. Surg., 2018, vol. 10, no. 4, pp. 448-454. DOI: 10.4055/cios.2018.10.4.448.

17.Bendella H., Rink S., Wöhler A., Feiser J., Wilden A., Grosheva M., Stoffels H.J., Meyer C., Manthou M., Nakamura M., Angelov D.N. Anatomic conditions for bypass surgery between rostral (T7-T9) and caudal (L2, L4, S1) ventral roots to treat paralysis after spinal cord injury. Ann. Anat., 2019, vol. 222, pp. 139-145. DOI: 10.1016/j.anat.2018.12.008.

18.Curt A., Van Hedel H.J., Klaus D., Dietz V.; EM-SCI Study Group. Recovery from a spinal cord injury: significance of compensation, neural plasticity, and repair. J. Neurotrauma, 2008, vol. 25, no. 6, pp. 677-685. DOI: 10.1089/neu.2007.0468.

19.Bedi P.K., Arumugam N., Chhabra H.S. Effectiveness of activity-based therapy in comparison with surface spinal stimulation in people with traumatic incomplete spinal cord injury for activation of central pattern generator for locomotion: Study Protocol for a 24-week Randomized Controlled Trial. Asian Spine J., 2018, vol. 12, no. 3, pp. 503-510. DOI: 10.4184/asj.2018.12.3.503.

20.Wagner F.B., Mignardot J.B., Le Goff-Mignardot C.G., Demesmaeker R., Komi S., Capogrosso M., Rowald A., Seáñez I., Caban M., Pirondini E., Vat M., McCracken L.A., Heimgartner R., Fodor I., Watrin A., Seguin P., Paoles E., Van Den Keybus K., Eberle G., Schurch B., Pralong E., Becce F., Buse N., Buschman R., Neufeld E., Kuster N., Carda S., Von Zitzewitz J., Delattre V., Prior J., Denison T., Lambert H., Minassian K., Bloch J., Courtine G. Targeted neurotechnology restores walking in humans with spinal cord injury. Nature, 2018, vol. 563, no. 7729, pp. 65-71. DOI: 10.1038/s41586-018-0649-2.

21.Minassian K., Hofstoetter U.S., Danner S.M., Mayr W., Bruce J.A., McKay W.B., Tansey K.E. Spinal rhythm generation by stepinduced feedback and transcutaneous posterior root stimulation in complete spinal cord-injured individuals. Neurorehabil. Neural Repair, 2016, vol. 30, no. 3, pp. 233-243. DOI: 10.1177/1545968315591706.

22.Nardone R., Höller Y., Taylor A., Thomschewski A., Orioli A., Frey V., Trinka E., Brigo F. Noninvasive Spinal Cord Stimulation: Technical Aspects and Therapeutic Applications. Neuromodulation, 2015, vol. 18, no. 7, pp. 580-591. DOI: 10.1111/ner.12332.

23.Hofstoetter U.S., Krenn M., Danner S.M., Hofer C., Kern H., McKay W.B., Mayr W., Minassian K. Augmentation of Voluntary Locomotor Activity by Transcutaneous Spinal Cord Stimulation in Motor-Incomplete Spinal Cord-Injured Individuals. Artif. Organs, 2015, vol. 39, no. 10, pp. E176-E186. DOI: 10.1111/aor.12615.

24.Hardin E.C., Kobetic R., Triolo R.J. Ambulation and spinal cord injury. Phys. Med. Rehabil. Clin. N. Am., 2013, vol. 24, no. 2, pp. 355-370. DOI: 10.1016/j.pmr.2012.11.002.

25.Herman R., He J., D’Luzansky S., Willis W., Dilli S. Spinal cord stimulation facilitates functional walking in a chronic, incomplete spinal cord injured. Spinal Cord, 2002, vol. 40, no. 2, pp. 65-68. DOI: 10.1038/sj.sc.3101263

26.Carhart M.R., He J., Herman R., D’Luzansky S., Willis W.T. Epidural spinal-cord stimulation facilitates recovery of functional walking following incomplete spinal-cord injury. IEEE Trans. Neural Syst. Rehabil. Eng., 2004, vol. 12, no. 1, pp. 32-42. DOI: 10.1109/TNSRE.2003.822763. 
Benij Ortopedii, Vol. 26, no 1, 2020

27.Behrman A.L., Harkema S.J. Physical rehabilitation as an agent for recovery after spinal cord injury. Phys. Med. Rehabil. Clin. N. Am., 2007, vol. 18, no. 2, pp. 183-202. DOI: 10.1016/j.pmr.2007.02.002.

28.Deng Y., Dong Y., Liu Y., Zhang Q., Guan X., Chen X., Li M., Xu L., Yang C. A systematic review of clinical studies on electrical stimulation therapy for patients with neurogenic bowel dysfunction after spinal cord injury. Medicine, 2018, vol. 97, no. 41, pp. e12778. DOI: 10.1097/MD.0000000000012778.

29.Badhiwala J.H., Ahuja C.S., Fehlings M.G. Time is spine: a review of translational advances in spinal cord injury. J. Neurosurg. Spine, 2018, vol. 30, no. 1, pp. 1-18. DOI: 10.3171/2018.9.SPINE18682.

30.McDonald J.W., Becker D., Sadowsky C.L., Jane J.A. Sr., Conturo T.E., Schultz L.M. Late recovery following spinal cord injury. Case report and review of the literature. J. Neurosurg., 2002, vol. 97, no. 2 Suppl., pp. 252-265. DOI: 10.3171/spi.2002.97.3.0405.

Received: 06.11.2019

\section{Information about the authors:}

1.Aleksei G. Baindurashvili, M.D., Ph.D., Professor, Academician of RAS, The Turner Scientific and Research Institute for Children's Orthopedics, Saint Petersburg, Russian Federation, Email: turner01@mail.ru

2.Sergei V. Vissarionov, M.D., Ph.D., Professor, The Turner Scientific and Research Institute for Children's Orthopedics, Saint Petersburg, Russian Federation, Email: turner01@mail.ru

3. Sergei M. Belianchikov, M.D., Ph.D., The Turner Scientific and Research Institute for Children's Orthopedics, Saint Petersburg, Russian Federation, Email: beljanchikov@list.ru

4. Kirill A. Kartavenko, M.D., Ph.D.,

The Turner Scientific and Research Institute for Children's Orthopedics, Saint Petersburg, Russian Federation, Email: med-kart@yandex.ru

5. Irina Iu. Solokhina,

The Turner Scientific and Research Institute for Children's Orthopedics, Saint Petersburg, Russian Federation, Email: solokhina.irina@mail.ru

6. Aleksandr S. Kozyrev, M.D., Ph.D., The Turner Scientific and Research Institute for Children's Orthopedics, Saint Petersburg, Russian Federation, Email: alexkozirev@inbox.ru

7. Aleksandr M. Pukhov, Ph.D. of Biological Sciences,

The Velikiye Luki State Academy of Physical Culture and Sports, Velikiye Luki, Russian Federation

8. Tatiana R. Moshonkina, Ph.D. of Biological Sciences,

Pavlov First St. Petersburg State Medical University, Saint Petersburg, Russian Federation, Email: tmoshonkina@gmail.com

9. Iurii P. Gerasimenko, Ph.D. of Biological Sciences, Professor, Corresponding Member of RAS, Pavlov First St. Petersburg State Medical University, Saint Petersburg, Russian Federation, Email: yuryg@ucla.edu 